\title{
Intraosseous terminal phalanx epidermoid inclusion cyst: a first case of late recurrence
}

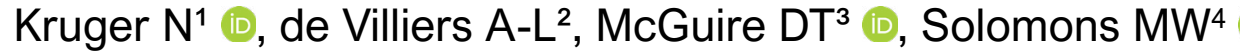 \\ 1 MBChB(UCT), MSc Diag Imaging (OXON), MSc (res) Orth (OXON), MMed Orth (UCT), FCS Orth (SA); Martin Singer Hand Unit, Groote Schuur \\ Hospital, University of Cape Town, South Africa \\ 2 MBChB, MMEd Anat Path; Umane Pathology Inc, Cape Town, South Africa \\ 3 MBBCh(Wits), MMed Orth (UCT), FCS Orth (SA); Martin Singer Hand Unit, Groote Schuur Hospital, University of Cape Town, South Africa \\ $4 \mathrm{MBChB}(\mathrm{UCT})$, FCS Orth (SA); Professor and HOD, Martin Singer Hand Unit, Groote Schuur Hospital, University of Cape Town, South Africa
}

Corresponding author: Dr Neil Kruger, Martin Singer Hand Unit, J60 Outpatients Building, Groote Schuur Hospital, Main Rd, Observatory, Cape Town, 7925; tel: 021404 5309; mobile: 079 3782480; email: neilkruger6@gmail.com

\begin{abstract}
Introduction: Epidermoid inclusion cysts (EIC) of the terminal phalanx are a rare but relevant cause of lytic lesions, particularly in the context of previous trauma to the finger. We report the first known case of late recurrence, occurring almost three decades after the incident surgery.

Methods: A 56-year-old female patient presented to us with what proved to be a histologically confirmed EIC of the terminal phalanx of her ring finger, but mentioned that she was treated for the same problem some 29 years ago. Medical archive reports and the histological slide from the incident surgery confirmed an initial EIC diagnosis, for which she was treated with curettage and iliac crest autograft, recovering uneventfully.

Results: Despite the 'zero' risk of recurrence, she elected to have ablative surgery through the distal interphalangeal joint and recovered well.

Conclusion: Care should be taken when counselling patients about possible recurrence of an EIC of the terminal phalanx, and that this recurrence may be many years after the index procedure.
\end{abstract}

Level of evidence: Level 5

Key words: intraosseous, epidermoid, inclusion cyst, enchondroma, phalanx tumour

Citation: Kruger N, de Villiers A-L, McGuire DT, Solomons MW. Intraosseous terminal phalanx epidermoid inclusion cyst: a first case of late recurrence. SA Orthop J 2019;18(2):49-52. http://dx.doi.org/10.17159/2309-8309/2019/v18n2a6

Editor: Dr A Ikram, Stellenbosch University, Cape Town, South Africa

Received: November 2018

Accepted: January 2019

Published: May 2019

Copyright: () 2019 Kruger N, et al. This is an open-access article distributed under the terms of the Creative Commons Attribution Licence, which permits unrestricted use, distribution and reproduction in any medium, provided the original author and source are credited.

Funding: This research received no funding.

Conflict of interest: All authors state that they have no conflict of interest with respect to this study. 


\section{Introduction}

Epidermoid inclusion cysts (EIC) of the bone are a rare but recognised cause for lytic lesions involving the terminal phalanx, particularly in the context of previous digital trauma. We report the first known case of late recurrence of an EIC in the terminal phalanx, occurring 29 years after initial curettage and iliac crest autograft.

\section{Methods and result}

An otherwise fit and healthy 56-year-old female presented to our hand unit with spontaneous onset, increasing right ring finger pain and swelling over the distal phalanx for the past six months. Notably, at age 3 years she had caught her finger in a door hinge and sustained a crush injury to the terminal phalanx. Despite some very mild tip sensitivity following this, she had a completely normally functioning finger. In 1986, at age 27 , she had first presented with a similar history and an X-ray that showed a lytic lesion of the terminal phalanx for which she underwent curettage and iliac crest autograft, recovering uneventfully. Intra-operative findings noted 'sebaceous type material and cyst lining removed' (Figure 1). Histology later confirmed an epidermoid inclusion cyst.

Twenty-nine years following this, she then represented with a very similar history, however denying any intercurrent finger trauma. Clinical exam revealed a mildly swollen terminal phalanx with increased sensitivity to touch. She had a normal range of motion of the distal interphalangeal joint.

$X$-ray revealed an expansile lesion involving the whole of the distal phalanx, with multiple lytic areas throughout, breeching the cortex distally and radially. Generalised cortical thinning and associated surrounding soft tissue swelling were also noted (Figure 2).

A discussion was had with the patient regarding revision curettage and grafting. She was adamant that even if the lesion was benign, the repeat hassle and cosmetic abnormality that the finger had brought her was an indication for terminalisation. If the histology came back as a malignancy (e.g. chondrosarcoma) she understood the need for a more proximal resection margin. She thus elected to have the terminal phalanx ablated, and recovered well. Pathology showed areas of keratin-lined cyst with surrounding foreign body reaction which again confirmed the diagnosis of an EIC (Figure 3).

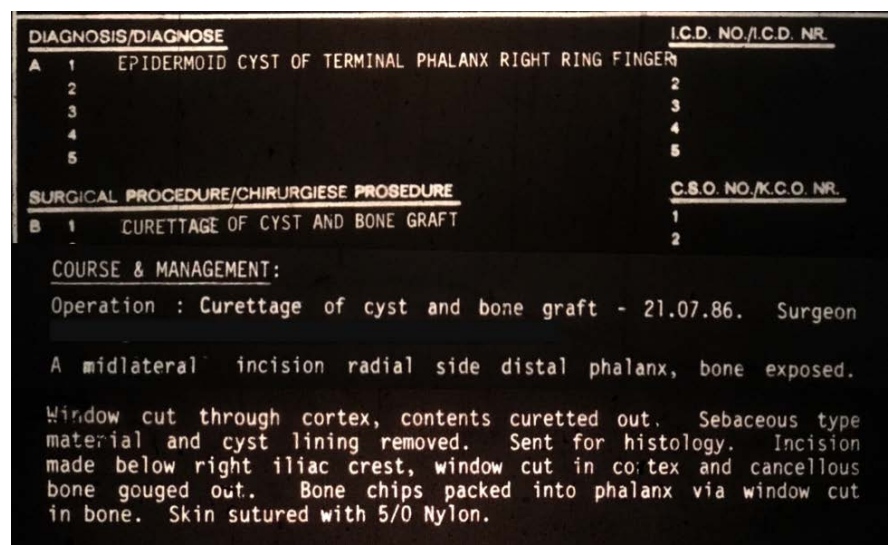

Figure 1. A photograph of the original microfilmed operative notes from 1986

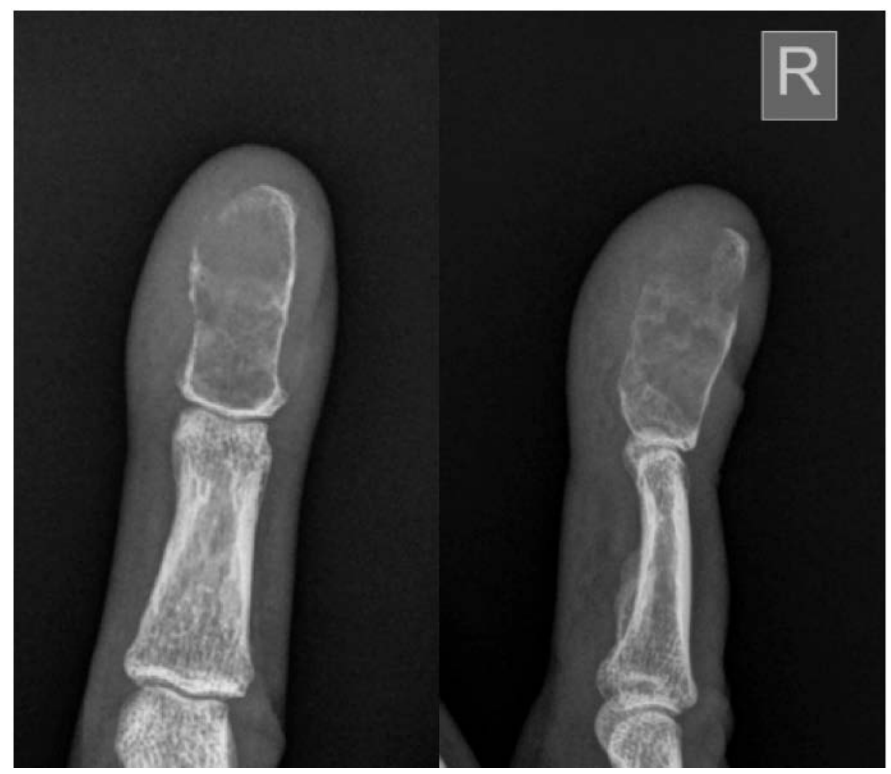

Figure 2. An anteroposterior and lateral X-ray showing the diffuse lytic lesion, noting the EIC diagnosis and detailing the findings accompanied by cortical thinning and cortical breeches. Note the absence of a periosteal reaction.

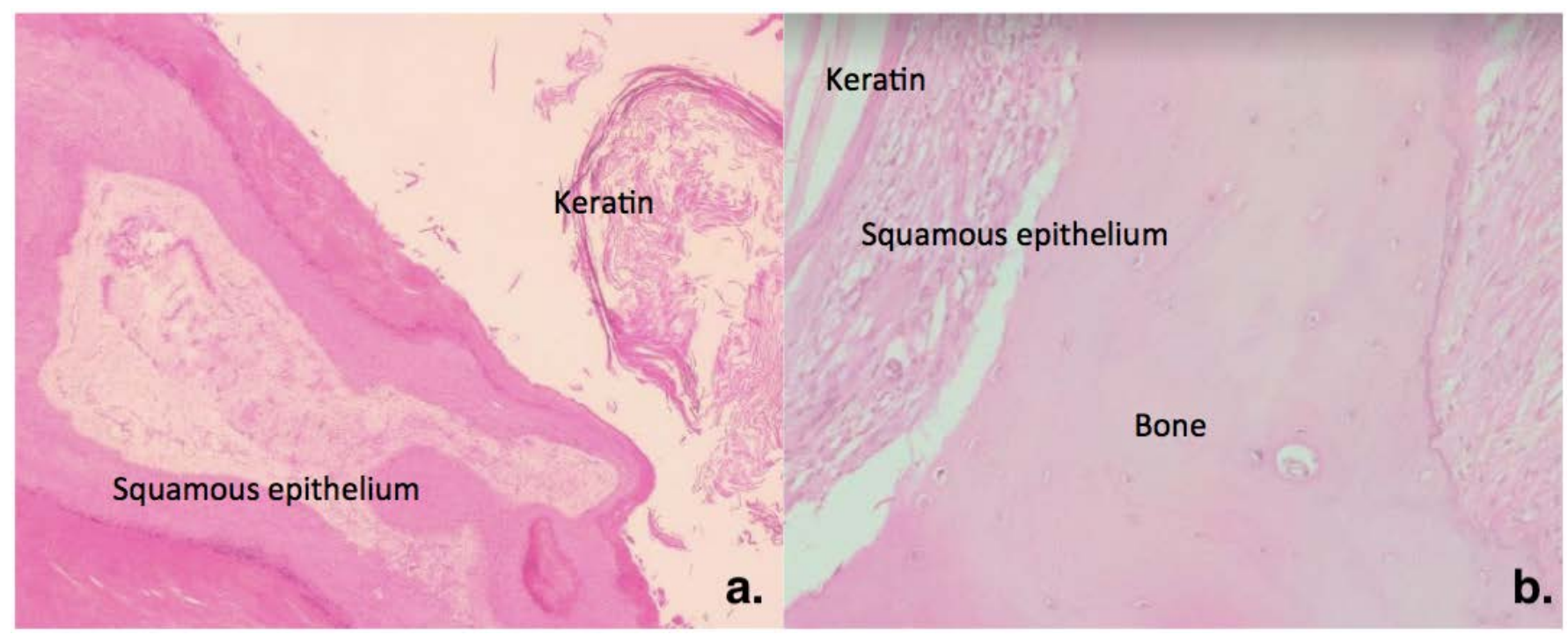

Figure 3. Histological slides of the original lesion (a) from 1986, and the recurrent lesion (b) confirming the diagnosis of an intraosseous epidermoid inclusion cyst 
Table I: A differential diagnosis of lytic lesions occurring in the distal phalanx

\begin{tabular}{|l|l|l|}
\hline Differential diagnosis & Benign & $\begin{array}{l}\text { Enchondroma } \\
\text { Osteochondroma }\end{array}$ \\
\hline Tumours & & \begin{tabular}{l} 
Aneurysmal bone cyst \\
Giant cell tumour \\
Simple bone cyst \\
\hline
\end{tabular} \\
\hline Tumour-like conditions & Malignant & Osteoid osteoma \\
\hline & & Metastasis - squamous carcinoma of the lung \\
\hline Infection & Glomus tumour & Ewing sarcoma \\
\hline Systemic manifestation of diseases & Intraosseous ganglion/synovial cyst & \\
\hline Metabolic & Epidermoid inclusion cyst & \\
\hline & Giant cell tumour of tendon sheath & \\
\hline & Giant call reparative granuloma & \\
\hline & Osteomyelitis & \\
\hline & Tuberculosis & \\
\hline
\end{tabular}

\section{Discussion}

The differential diagnosis for lytic lesions involving the distal phalanx is broad, and encompasses benign and malignant tumours, as well as tumour-like conditions and infection (Table I).

EICs account for such a lytic radiographic appearance but are rare pseudotumours. Jamshidi et al., at a tertiary referral centre, over a five-year period, reviewed 14 patients presenting with a lytic lesion of the terminal phalanx and found only one to be an intraosseous EIC. ${ }^{1}$ They occur predominantly in middle-aged adults, and more in males than in females. ${ }^{2,3}$ They are also distinctively associated with previous trauma to the digit in almost half the cases ${ }^{4,5}$ and this most likely explains both the male preponderance and terminal phalanx as the most common site, it being the most frequently injured part of the finger. Infrequently the cyst arises spontaneously, and this is thought to be from congenital intraosseous inclusion of epidermoid cells.

The time from either post-traumatic or iatrogenic intraosseous epidermoid cell introduction to clinical presentation is from months to many years. To our knowledge only one case of recurrence has been reported, ${ }^{6}$ occurring one year after the initial surgery. This recurrence occurred 29 years later, and it remains uncertain as to why this variability exists or what inciting event induces the cellular proliferation to form mature keratin-producing cysts.

Clinically the patients usually present with gradually increasing pain and mild swelling, but may present more acutely post pathological fracture. There may be accompanying nail deformity with pseudoclubbing, or erythema. ${ }^{4}$

Radiographically they resemble enchondromas in appearance, but may be differentiated from them by location, as enchondromas usually occur closer to the base of the phalanx, and often have intralesional calcification. Typically they are expansile lytic lesions with cortical thinning and little to no trabecular pattern. ${ }^{7}$ An absence of periosteal reaction helps to differentiate from osteomyelitis.

Histology is needed for definitive diagnosis and may be obtained through needle aspiration if enough keratin or sebaceous material is present. $^{8}$ More often definitive treatment and diagnosis are undertaken concurrently with excision biopsy through curettage, and bone grafting of the defect if indicated.

\section{Conclusion}

Significantly, to our knowledge, this is the first reported case of late recurrence of an EIC of the distal phalanx in the literature. It recurred almost three decades after the initial surgery, and care should be taken in counselling patients about possible late recurrence.

\section{Ethics statement}

All procedures followed were in accordance with the ethical standards of the responsible committee on human experimentation (institutional and national) and with the Helsinki Declaration of 1975, as revised in 2008. Verbal informed consent was obtained from the patient prior to undertaking the study and all data was anonymised.

\section{Declaration}

The authors declare authorship of this article and that they have followed sound scientific research practice. This research is original and does not transgress plagiarism policies.

\section{Acknowledgements}

Thanks to the patients for their assistance in providing detailed information and allowing access to records for manuscript preparation.

\section{Author contributions}

NK collected the microfilm data, drafted and edited the manuscript.

A-LdV provided the slides and interpretation thereof, and edited the manuscript.

DTM assisted with data collection and edited the manuscript.

MWS provided the original study concept, assisted with data collection and edited the manuscript.

\section{ORCID}

Kruger N iD https://orcid.org/0000-0002-0929-2092

McGuire DT (ID) https://orcid.org/0000-0001-5149-8708

Solomons MW iD https://orcid.org/0000-0002-4642-3311

\section{References}

1. Jamshidi K, Mazhar FN, Jafari D. Lytic lesion in the distal phalanx of the hand. Shafa Orthopaedic Journal. 2015;2(1):e441. 
2. Hamad AT, Kumar A, Anand Kumar C. Intraosseous epidermoid cyst of the finger phalanx: a case report. $J$ Orthop Surg (Hong Kong). 2006;14(3):340-42.

3. Lerner MR, Southwick WO. Keratin cysts in phalangeal bones. Report of an unusual case. J Bone Joint Surg Am. 1968;50(2):365-72.

4. Kalsotra N, Singh M, Sharma S, Singh D. Intraosseous epidermoid cyst of the finger phalanx: a case report. Orthopaedic Research and Reviews. 2010;2:71-73.

5. McGraw P, Bonvento B, Moholkar K. Phalangeal intraosseous epidermoid cyst. Acta Orthop Belg. 2004;70(4):365-67.

6. Kurosawa K, Kobayashi R, Takagishi K. Distal phalangeal reconstruction for recurrent intraosseous epidermoid cyst of the finger - a case report. Hand Surg. 2011;16(3):375-77.

7. Ruchelsman DE, Laino DK, Chhor KS, Steiner GC, Kenan S. Digital intraosseous epidermoid inclusion cyst of the distal phalanx. $J$ Hand Microsurg. 2010;2(1):24-27.

8. Handa U, Kumar S, Mohan H. Aspiration cytology of epidermoid cyst of terminal phalanx. Diagn Cytopathol. 2002;26(4):266-67. 